J. Clin. Chem. Clin. Biochem.

Vol. 17, 1979, pp. 97-99

\title{
2,3-Dihydroxybutane: An Unusual Compound Found in the Gaschromatographic Analysis of Volatile Compounds of Urine
}

\author{
By F. A. Hommes,
}

Department of Paediatrics, University of Groningen,

A. P. Bruins,

Department of Pharmacy, University of Groningen,

\section{J. Dajani-Wielaard,}

Department of Paediatrics, University of Leiden,

and $R$. Baarsma,

Department of Paediatrics, University of Groningen, The Netherlands

(Received April 28/September 1, 1978)

Summary: 2,3-Dihydroxybutane, a compound not observed in normal urines, was identified in the urine of two patients by combined gas chromatography-mass spectrometry. It is suggested, that this 2,3-dihydroxybutane is derived from pyruvate by bacterial metabolism.

\section{2,3-Dihydroxybutan: Eine ungewöhnliche Verbindung, gefunden bei der gaschromatographischen Analyse flüchtiger Verbindungen des Harns}

Zusammenfassung: 2,3-Dihydroxybutan, eine im normalen Harn nicht beobachtete Verbindung, wurde durch Gaschromatographie-Massenspektrometrie im Harn zweier Patienten identifiziert. Es wird angenommen, daß 2,3Dihydroxybutan durch bakteriellen Stoffwechsel aus Pyruvat entsteht.

\section{Introduction}

Gas chromatography has proved to be a powerful technique for the identification of normal and abnormal metabolitès in human body fluids and urine. In most cases compounds can be identified as being derived from normal or deranged human metabolism, but some examples are known of compounds in urine whose origin must be exogenous $(1-4)$, the latest additions to this lișt being laevulinic acid (5) and 2-ethoxy-ethoxy-acetic acid (6). In this communication the identification of 2,3-dihydroxybutane is described.

\section{Materials and Methods}

\section{Patients}

Case 1 (patient R.) was born after an uneventfuli pregnancy with a birth weight of $2510 \mathrm{~g}$. Except for increased muscle tone and irritability no abnormalities were noted. Blood levels of glucose, calcium and magnesium were normal. When the child was 9 days old he became apathetic and vomited. No cause was found and he recovered rapidly after the modified milk feedings had been substituted by intravenous glucose and fat emulsions. Blood and urine examinations were normal, except for a low urea level (blood urea nitrogen $47 \mathrm{mg} / \mathrm{l}$ ), a slightly increased ammonia level ( $1.8 \mathrm{mg} / \mathrm{l}$ ) and a metabolic acidosis ( $\mathrm{pH} 7.30$ ). Amino acids were normal as was urinary lactate excretion. After 2 days, oral feeding was reinstituted, and the clinical condition was satisfactory, although increased muscle tone and irritability persisted. Concentrations of amino acids and pyruvate in cerebrospinal fluid were within normal limits. During the following weeks repeated blood investigations all gave normal results, but the unexplained metabolic acidosis persisted for 2 weeks. Diarrhoea never occurred. During this period, a 24 hour urine sample was sent to the laboratory for investigation of organic acids and 2,3-dihydroxybutane was then detected. Without further treatment the acidosis disappeared and the child was discharged. During follow-up he did well and after $2 \frac{1}{2}$ months muscle tone became normal. Development was unimpaired.

Case 2 was born after a pregnancy of 33 weeks, with a birth weight of $1800 \mathrm{~g}$. A metabolic acidosis (pH 7.20) was observed during the first week of life which was corrected with intra- 
venous sodium hydrogencarbonate. All other clinical chemical parameters. which included blood amino acids, blood lactate and pyruvate and glucose, were within normal limits. During this period of acidosis, urine was analysed for organic acids and 2,3-dihydroxybutane was found. The child was slightly apathetic. The acidosis disappeared without further treatment and the child was discharged after two weeks. After the period of acidosis, the 2,3-dihydroxybutane could not be detected again in the urine.

\section{Procedure}

Volatile and non volatile compounds of urine were analysed as described previously $(7,8)$. Urines were stored at $-70^{\circ} \mathrm{C}$ until analysis. Mass spectrometry was carried out on a Finnigan 3300 GCMS system equipped with the standard all glass jet separator and standard electron impact source. A $2.2 \mathrm{~m} \times 2 \mathrm{~mm}$ i.d. glass column packed with $20 \%$ NPGA and $2 \% \mathrm{H}_{3} \mathrm{PO}_{4}$ on Gas Chrom Q 80-100 mesh was used with $\mathrm{He}$ as the carrier gas at $30 \mathrm{ml} /$ min. Mass spectra were processed by the Finnigan 6100 data system.

\section{Results and Discussion}

Figure 1 shows the gas chromatogram of the volatile compounds of the urine of the first patient. Besides small amounts of formic acid, acetic acid and propionic acid with retention times of $0.19,0.22$ and 0.36 respectively, with respect to the internal standard (2methyl-n-butyric acid), a large fraction with a retention time of 0.62 can be observed. This fraction is asymmetric. The column used for the identification of volatile components in urine (7) has however been designed primarily for the analysis of short chain fatty acids.

Mass spectrometry identified this compound as 2,3dihydroxy-butane, as is illustrated in figure 2 . The mass spectrum of the compound with retention time 0.62 (fig. 2 top) was identical to that of authentic 2,3dihydroxybutane (fig. 2 bottom). Authentic 2,3-dihydroxybutane yielded a gas chromatogram identical to that given by the urine fraction with a relative retention time of 0.62 , and the same typical peak asymmetry. The molecular weight of 2,3-dihydroxybutane is 90 . The peaks, observed in the mass spectrum with $\mathrm{m} / \mathrm{e}$ values

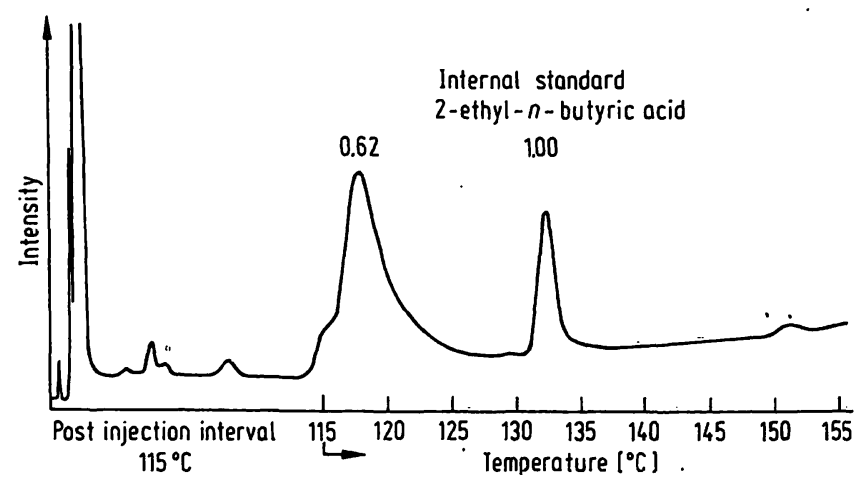

Fig. 1. Gas chromatogram of the volatile compounds of the urine of the first patient. I. St. = Internal standard $=2$ ethyl-n-butyric acid.
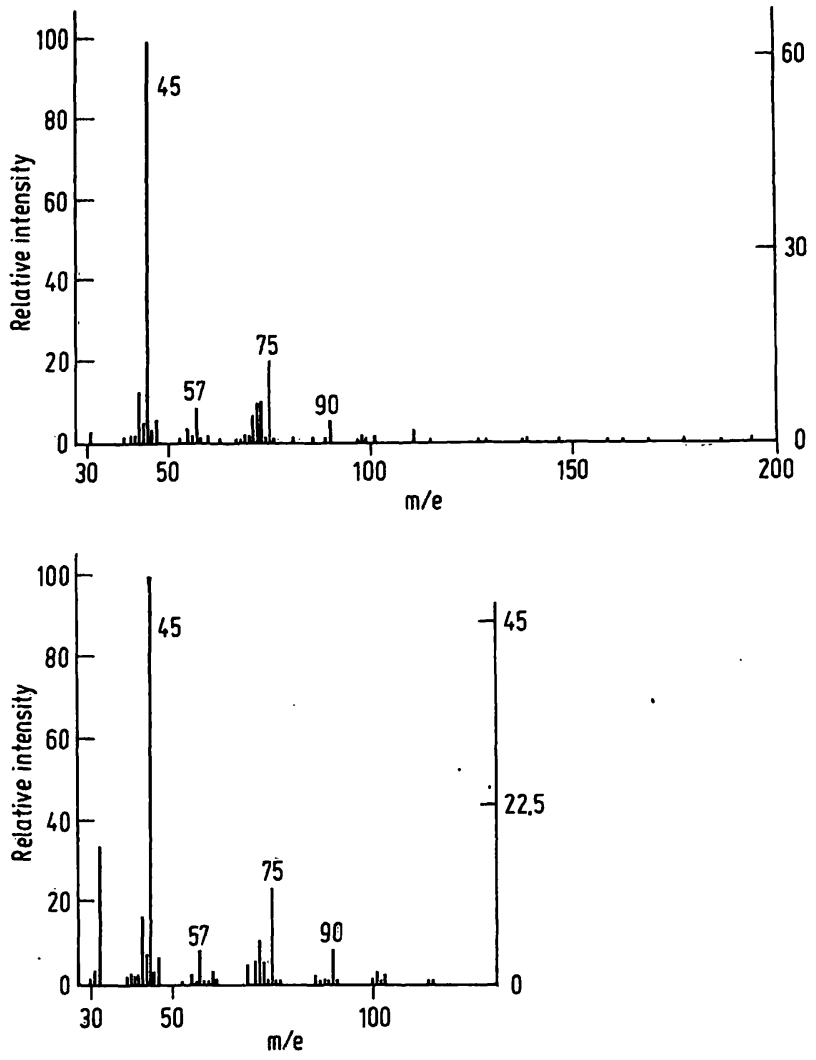

Fig. 2. Masss spectra of the compound of the gas chromatogram of figure 1 with relative retention time of 0.62 (top) and of authentic 2,3-dihydroxybutane (bottom). Cleavage of the $\mathrm{C}_{2}-\mathrm{C}_{3}$ bond produces the base peak at $\mathrm{m} / \mathrm{e} 45$. Peaks $>60$ are magnified 10 times.

higher than 90 , are due to column bleeding. The mass spectrum of the urinary compound with a relative retention time of 0.62 , the spectrum of an authentic sample of 2,3-dihydroxybutane, and the published mass spectrum of 2,3-dihydroxybutane (9) were identical.

No other abnormal metabolites were observed in the patient's urine by gas chromatography for volatile or non volatile compounds. The gas chromatogram of the volatile compounds of the urine of the second patient was virtually identical to that of the first patient. The gas chromatogram of the nonvolatile compounds yielded likewise no indication for the presence of abnormal metabolites, except for the trimethylsilyl derivative of 2,3-dihydroxybutane. The 2,3-dihydroxybutane could be of bacterial origin. Several bacteria, including $E$. coli contain acetolactate synthetase, which converts pyruvate to acetolactate. This acetolactate is decarboxylated to acetoin which can be reduced to the diol by butanediol dehydrogenase (for review c.f. l.c. (10)). The mammalian liver is, however, also able to form acetoin from pyruvate or ethanol (11-13) via the action of pyruvate decarboxylase; furthermore, acetoin can be reduced to 2,3-dihydroxybutane (13). It could be speculated that an overflow of the pyruvate decarboxylase reaction results in the formation of acetoin and 2,3-dihydroxybutane. 
Since both patients developed normally, the occurrence of 2,3-dihydroxybutane does not seem to be harmful. During the investigation of patients suspected of inborn errors of metabolism unknown compounds are frequently observed in the gas chromatograms of urine or blood. The determination of the structure is essential because of its possible endogenous origin, which may give a clue to the nature of the defect. Future evaluation of gaschromatograms have now to take into account the possible occurrence of 2,3-dihydroxybutane, which is presumably of exogenous origin.

\section{References}

1. Armstrong, M. D. \& Shaw, K. N. F. (1957), J. Biol. Chem. 225, 269-278.

2. Bindel, T. H., Ternessey, P. V., Miles, B. S. \& Goodman, S. I. (1976), Clin. Chim. Acta 66, 209-219.

3. Mrochek, J. E. \& Rainey, W. T. (1972), Clin. Chem. 18, 821-828.

4. Fell, V., Lee, C. R. \& Pollitt, R. J. (1975), Biochem. Med. $13,40-45$.

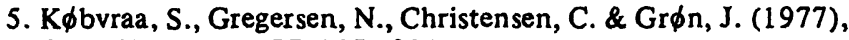
Clin. Chim. Acta 77, 197-201.

6. Kamerling, J. P., Duran, M., Bruinvis, L., Ketting, D., Wadman, S. K., De Groot, C J. \& Hommes, F. A. (1977), Clin. Chim. Acta 77, 397-405.

7. Van den Berg, H. \& Hommes, F. A. (1974), Clin. Chim. Acta $51,225-232$.
8. Van den Berg, H., Boelkens, M. Th. E. \& Hommes, F. A. (1976), Acta Paediatr. Scand. 65, 113-118.

9. Stanhagen, E., Abrahamson, S. \& Mc. Lafferty, F. W. (1974), Registry of Mass Spectral Data, Vol. 1, 60, John Wiley, New York.

10. Stormer, F. C. (1975), Meth. Enzymol. 41, 518-533, Acad. Press, New York.

11. Labin, M. \& Westerveld, W. W. (1945), J. Biol. Chem. 161, 503-512.

12. Dawson, Y. \& Hullin, B. P. (1954), Biochem. J. 57, 177185.

13. Gabriel, M. A., Jabora, H. \& Al-Khalidi, U.A.S. (1971), Biochem. J. 124, 793-800.

\section{F. A. Hommes and R. Baarsma}

Laboratory of Developmental Biochemistry Department of Paediatrics / University of Groningen 10 , Bloemsingel

$9712 \mathrm{KZ}$ Groningen

The Netherlands

\section{A. P. Bruins}

Laboratory of Pharmacy and Analytical Chemistry 2, Ant. Deusinglaan/University of Groningen 9713 AW Groningen

The Netherlands

J. Dajani-Wielaard Department of Paediatrics University of Leiden

10, Rijnsbergerweg

2333 AA Leiden

The Netherlands 